\title{
A study on homemakers' preference for ceramic surface cleansing agents in Ludhiana city
}

\author{
RITIKA DIXIT, SURINDERJIT KAUR AND R. BAKHSHI
}

Received: 06.08.2014; Revised: 30.10.2014; Accepted: 14.11.2014

See end of the paper for authors' affiliations RITIKA DIXIT

Department of Family Resource Management, Punjab Agricultural University, LUDHIANA (PUNJAB) INDIA

Email:shilpitheangel.dixit@gmail. com
ABSTRACT : Detergent cakes and washing powders have become an inseparable part of every homemaker's life (Vajpeyi, 1999). The market offers a variety of cleansing agents. A variety of cleansing agents such as synthetic cleaners, detergent powders, acidic and alkaline cleaners are available in the market. Different methods of cleaning are followed in each household and accordingly the preference for cleansing agents varies. The present study was conducted to know the consumption pattern of cleansing agents among respondents and problems experienced while using these. The study was conducted on sample of sixty respondents from two localities of Ludhiana city, selected by using simple random sampling technique. The data were collected through personal interview using interview schedule. The results of the survey revealed that commercial liquid cleansing agents were found to be the most popularly used cleansing agents for household cleaning. The average quantity of commercial liquid cleansers being used was $1.761 /$ month and average monthly expenditure on these cleaners was Rs. 102. Floor tiles and toilet bowls were washed daily by more that 50 per cent of respondents. As high as 80 per cent of respondents faced the problem of dryness of skin by using detergent powder, around 22.0 per cent respondents reported breathing problems by using commercial liquid cleansing agents.

KEY WORDS: Cleansing agents, Consumption, Cleansing efficiency, Liquid cleansing agents

- HOW TO CITE THIS PAPER : Dixit, Ritika, Kaur, Surinderjit and Bakhshi, R. (2014). A study on homemakers' preference for ceramic surface cleansing agents in Ludhiana city. Asian J. Home Sci., 9 (2) : 523-526. 